\title{
RELACIÓN PROFESOR-ALUMNO EN LA UNIVERSIDAD: ARISTA FUNDAMENTAL PARA EL APRENDIZAJE
}

\section{Introducción}

De acuerdo a la tendencia mundial, en los últimos 30 años en Chile la oferta de instituciones de educación superior aumentó considerablemente favoreciendo el acceso a ésta de grupos sociales cada vez más diversos (IESALC, 2006). Sólo entre 1990 y el año 2003 la cobertura de la población entre 18 y 24 años pasó del 16\% al 37,5\%, proyectándose para 2012 una cobertura del 50\%. Las expectativas de desarrollo del país permiten augurar la continuidad e incremento de este fenómeno en los próximos años (González \& Uribe, 2002).

La masificación y diversificación de la educación superior ha implicado distintos desafíos para las universidades, tanto en Chile como en el mundo. Uno de éstos ha sido hacerse cargo de la creciente heterogeneidad de su estudiantado. Hoy en día, la población universitaria toma rostro dibujada por la diversidad presente entre sus estudiantes. Representantes de grupos sociales históricamente excluidos de la educación terciaria, estudiantes lejanos al perfil homogéneo de alumno que por años se ha formado en las universidades, distintos de "los de siempre" y también entre sí, se encuentran en las aulas con otros estudiantes a los que podría llamarse "tradicionales", portadores de un alto capital cultural, provenientes de un estrato social medio o alto e idóneos en una serie de habilidades necesarias para desenvolverse con éxito en la educación postsecundaria (Canales \& De los Ríos, 2007; Donoso \& Cancino, 2007).

Las principales dificultades asociadas a educar en la diversidad asumida por las universidades se relacionan con generar mecanismos que favorezcan la permanencia de los estudiantes en el sistema y la detección temprana de dificultades al respecto; promover el compromiso e involucramiento con sus carreras, definir actividades 
en el aula "al alcance de todos y que, al mismo tiempo, constituyan un desafío de aprendizaje para todos" (Sebastián, 2007, p. 85) y también, ser capaces de utilizar la multiplicidad como un recurso para la enseñanza.

Actualmente las universidades no estarían capacitadas para desarrollar prácticas que asegurasen que las diferencias entre los estudiantes a su ingreso a la universidad no determinen en gran medida sus resultados académicos y adquisición de competencias requeridas, "la institucionalidad no estaría ofreciendo oportunidades equivalentes a cada estudiante según sus especificidades, sino que, en la práctica, estaría discriminando a favor de unos y en contra de otros" (Sebastián \& Scharager, 2007, p. 23).

Para Unesco (1998), sería un deber de las universidades dar una adecuada respuesta a los cambios experimentados en su estudiantado, modificando para ello modelos educativos centrados en la transmisión de contenidos por modelos de enseñanza innovadores, adaptados a las características y necesidades de estudiantes diversos, favoreciendo su retención y permanencia en la universidad, considerándolos como el centro y los protagonistas del proceso de renovación en movimiento. Este nuevo contexto de acción para las universidades demandaría acciones coordinadas de distintos actores de la gestión: directivos, profesores, administrativos y unidades preocupadas del bienestar psicosocial y académico de los estudiantes estarían llamados a asumir tareas al respecto.

En este punto cabe destacar el papel de los docentes frente a los cambios en la población que accede a la educación superior. Este resulta particularmente sensible y relevante pues son el "rostro visible" de las universidades frente a sus alumnos, y tienen en sus manos el potencial de abrir las puertas del mundo universitario a los nuevos estudiantes. Los docentes pueden generar cambios importantes en la historia de aprendizaje de sus alumnos, tienen la capacidad y el potencial para acogerlos y motivar en ellos el deseo por aprender y desarrollarse en la universidad, aportando a la creación de una educación superior terciaria de mayor calidad y equidad (Berríos, 2007). 
No obstante lo anterior, y ser los docentes reconocidos como actores clave para avanzar en la construcción de una universidad más plural, acogedora, motivadora y exigente, existen algunos nudos presentes en gran parte de las instituciones en Chile que pueden amenazar o afectar su desempeño en relación con la enseñanza y sus estudiantes.

En general, los docentes universitarios no tienen formación pedagógica. Muchos utilizan un conocimiento educativo fundado en sus propias experiencias y un contexto de creencias estable sobre el que sostendrían sus prácticas y actitudes hacia los estudiantes. Lo anterior estaría relacionado con "la creencia mayoritaria, en la cultura iberoamericana, de que una sólida formación científica y profesional le basta al docente para transmitir los contenidos de su asignatura, desestimándose los saberes pedagógicos" (Krzemien \& Lombardo, 2006, p. 1).

- Como consecuencia de la masificación de la educación superior, también ha aumentado en forma creciente la demanda de profesores (Berríos, 2008), quienes por lo general se integran a la docencia con escasos o nulos procesos de inducción respecto al quehacer pedagógico universitario. No es sólo que no existan modelos comunes sobre cómo desarrollar procesos de enseñanzaaprendizaje en la universidad (cuya necesidad de existencia puede ser tema de otra reflexión), sino que, salvo contadas excepciones como el Centro de Desarrollo Docente, CDDOC UC, existen pocas orientaciones generales de cómo educar a jóvenes y adultos.

- Cada profesor es un "rey solitario" en su cátedra, teniendo pocas instancias de evaluación de pares o asesoría en aula. La evaluación docente es uno de los pocos instrumentos de retroalimentación ampliamente difundidos en las universidades, no obstante, su incidencia real en las prácticas educativas resultaría heterogénea. Tampoco existen espacios de reflexión pedagógica institucionalizada entre docentes (algo que sí se ha intencionado con fuerza en la educación básica y secundaria y valdría la pena preguntarse si tendría cabida en la educación superior o no). Cuando los profesores se reúnen a hablar de sus prácticas en aula y aprender entre sí es debido, por lo general, a motivaciones personales y de buena voluntad. 
- La función académica es demandada a una multiplicidad de roles y tareas, no siendo la docencia la prioridad. Si bien ésta es por exigencia general tarea de todo docente, los incentivos hacia su trabajo apuntan principalmente a la investigación y publicación y poco hacia la mejora de la enseñanza.

Si se valora el asegurar mejores procesos de enseñanzaaprendizaje en la educación superior, que favorezcan la retención y motivación de estudiantes diversos con sus carreras, un paso necesario sería fortalecer la función de los académicos en tanto educadores, entregando a ellos herramientas, orientaciones y conocimientos específicos de aprendizaje útiles para su encuentro con los alumnos y generar incentivos para su mejora constante (como el premio a la excelencia docente de la PUC o la Universidad Católica de Temuco), promoviendo instancias de reflexión conjunta respecto a la docencia e incluso definiendo con mayor claridad perfiles académicos especializados (Pedró, 2004, en Sebastián \& Scharager, 2007).

Uno de los caminos (en absoluto el único) para fortalecer la función docente de los académicos, y de este modo favorecer la acogida que las universidades ofrecen a sus nuevos estudiantes, sería generar orientaciones útiles para la práctica educativa, basadas en las experiencias de aprendizaje de los actuales estudiantes, que respondan a preguntas tales como ¿de qué manera un profesor puede llegar a sus alumnos, encantarlos con sus estudios y promover en ellos los mejores aprendizajes? ¿Cómo establecer una buena relación profesoralumno? ¿Qué acciones de la docencia desmotivan y los alejan del aprendizaje? Considerar su punto de vista puede ayudar en tal tarea (Cataldi \& Lage, 2004). Como señalara Bain (2004), si se quiere saber si hay algún aspecto en la educación recibida por los actuales estudiantes que les haya ayudado y motivado a aprender ¿por qué no preguntarle a ellos mismos?

Ingresar a las aulas y reconocer cómo es que los estudiantes aprenden mejor junto a sus profesores, abriendo líneas de investigación al respecto, considerando los procesos de enseñanza-aprendizaje como parte nuclear de la calidad en la educación superior puede significar un aporte en el actual desafío de cambios que enfrentan 
las universidades, haciendo así de un espacio antaño relegado a una elite a uno de crecimiento para todos.

El presente artículo pretende aportar al respecto. Se expondrán los hallazgos de una investigación desarrollada en la Pontificia Universidad Católica de Chile, PUC, que persiguió reconocer, desde la perspectiva de estudiantes de cinco carreras de pregrado (Arquitectura, Ciencias Biológicas, Educación, Ingeniería y Psicología), características de la relación profesor-alumno que a su juicio habrían facilitado su aprendizaje y compromiso académico y también aquellas que no habrían ayudado en estos aspectos, generando incluso malestar y descontento entre los universitarios. La investigación fue realizada en el contexto de trabajo del Observatorio de Juventud Universitaria de la Dirección General Estudiantil (DGE) de la PUC, apoyada por el Fondo de Desarrollo a la Docencia, FONDEDOC 2007-2008.

\section{Antecedentes}

La relación profesor-alumno emerge como una arista fundamental en el fenómeno educativo, refrendada tanto en el ámbito teórico como empírico. Ha sido caracterizada como uno de los componentes del clima social de aula, parte de los elementos que configurarían la invisible convivencia interna de un grupo orientado a aprender un conocimiento específico (Arón \& Milicic, 1999). Que el modo cotidiano de relacionarse entre aprendices y docentes sea "invisible" no implicaría que esta forma de vincularse no pueda llegar a ser intencionada, modificada y perfeccionada. Aprendices y maestros construirían día a día su relación pedagógica.

Esta relación ha sido definida y analizada generalmente como la interactividad desarrollada entre los participantes de un proceso de aprendizaje, reunidos "con el propósito de que las personas involucradas aprendan y aprendan determinadas cosas" (Casassus, 2006, p. 248). En el modelo del triángulo pedagógico de Houssaye (1988), la relación profesor-alumno correspondería a la conexión pedagógica entre el sujeto que enseña y los sujetos que aprenden (relación en la cual, siguiendo a Paulo Freire (1997), todos los participantes aprenden, educadores y educandos). Por su parte, Van Manem (1991) comprende 
la relación profesor-alumno como la interacción conjunta de tres dimensiones incorporadas en todo proceso de enseñanza-aprendizaje, ofreciendo más polos de análisis para comprender el fenómeno. Estas dimensiones serían las siguientes:

- Dimensión personal: incluiría tanto las características personales del profesor (su estilo, su sello, su edad) como las de quienes aprenden (sus trayectorias académicas previas, su edad, sus modos de aprender y elaborar el contenido que se les ofrece).

- Dimensión bidireccional: interacción social entre un sujeto que enseña y un sujeto o grupo de sujetos que aprenden, independiente del contenido que los reúne. Es ésta la dimensión a la que comúnmente se refieren los estudios que han investigado la relación profesor-alumno.

- Dimensión tripolar: se incluye en el análisis de la relación pedagógica un tercer componente mediador: el contenido a aprender. Éste impregna la relación, establece una jerarquía y una temporalidad al encuentro y estructura el tipo de contacto que se establece.

Otros estudios se refieren a esta última dimensión como las "estrategias instruccionales" utilizadas por el docente, influenciado en parte por el contenido que debe enseñar, distinguiendo entre éstas a las formas de organización del contenido, los medios utilizados, la organización de los alumnos para los fines de aprendizaje y la gerencia de recursos para la enseñanza (Smith \& Ragan, 1999).

Una buena relación pedagógica redundaría en mejores aprendizajes y en una experiencia académica satisfactoria para el estudiantado, evidencia rescatada en diversos estudios alrededor del mundo que han tomado a los estudiantes como fuente directa de información al respecto (Al-Hamdan, 2007; Rosh, 2006; Bain, 2004), incluyendo Latinoamérica (Krzemien \& Lombardo, 2006; Cataldi \& Lage, 2004; Batanaz, 1997) y Chile (Bennett, 1999).

Un clima social positivo, fruto de una buena relación pedagógica, facilitaría el aprendizaje y el reconocimiento mutuo entre los participantes implicados (Arón \& Milicic, 1999). El clima social, tanto si sea definido directamente como la enseñanza o como el clima 
general entre el instructor y el aprendiz, proveería a los estudiantes de soporte para el logro de sus aprendizajes esperados en el contexto de una formación específica (Coldren \& Hively, 2009).

Desde el marco teórico constructivista, se entiende que las características socioafectivas de la interacción social entre los participantes de un proceso de formación inciden en el aprendizaje, entendido éste como la acomodación de estructuras de conocimiento previas tanto de aprendices como de maestros, facilitada por la ocurrencia de conflicto cognitivo en el aula. Si bien éste se podría presentar tanto en contextos poco amenos como en ambientes gratos y acogedores de aprendizaje, sería en este último tipo de casos donde la probabilidad de acomodación sería mayor (Bourgeois \& Nizet, 1997, en Sebastián, 2007).

Pese a su importancia para el aprendizaje, una buena relación pedagógica no sería un elemento dado de por sí en el aula (sea en educación escolar, universitaria o de adultos). Debe existir disposición de los participantes para su construcción, en especial por parte de los docentes, pues serían ellos quienes ofrecerían las pautas generales para el desarrollo del vínculo a lo largo del tiempo.

Estudiantes universitarios, a la hora de referir características asociadas a una buena relación profesor-alumno dan cuenta de elementos principalmente sociales de la relación gestionadas por los académicos. Señalan importante el trato personalizado, amable y capaz de producir confianza en los estudiantes (Krzemien \& Lombardo, 2006; Bennett, 1999), valoran la generación de un contexto comunicativo acogedor y amistoso, basado en el respeto mutuo entre todos y la abstinencia de acciones que intimiden a los alumnos (Al-Hamdan, 2007). Dan especial importancia al sentirse reconocidos y valorados por sus profesores, lo cual favorecería su motivación y compromiso con el aprendizaje (Rosh, 2006). Todo lo reseñado se ubica en el espacio del aula, pero la relación con los docentes puede ir más allá: la interacción con docentes fuera del ámbito estrictamente formal promovería el desarrollo cognitivo de los estudiantes y mejores resultados académicos (Terenzini, Pascarella \& Blimbling, 1999). 
Por otro lado, existirían condiciones de base que enmarcan los actuales procesos de enseñanza que podrían afectar al establecimiento de una buena relación profesor-alumno, dificultando el encuentro entre docentes y estudiantes.

La falta de instancias de encuentro más allá de la cátedra (en especial con los llamados "profesores hora", sin horario de permanencia ni lugar físico disponible para recibir a sus alumnos) sería una de las condiciones que afectaría el vínculo.

A esta condición concreta se sumaría la brecha generacional existente entre profesores y alumnos, en ocasiones difícil de estrechar (y aun comprender por parte de los docentes) (Cataldi \& Lage, 2004; Bennett, 1999).

En contraste con generaciones anteriores, los actuales estudiantes diferirían en sus modos de relacionarse con el aprendizaje y de vincularse con sus figuras de autoridad. El uso avanzado de nuevas tecnologías de la información, a su alcance "desde la cuna", y la aspiración a relaciones más bien horizontales que verticales en el trato con sus profesores generarían diferencias importantes entre estos estudiantes y en aquellos en los cuales los docentes tenderían a pensar al diseñar sus clases y actividades académicas (en muchos casos una imagen similar a sí mismos como alumnos). Al respecto, un académico latinoamericano reflexionaba: "Seguramente no pocas veces hemos caído en el error de suponer que [los jóvenes universitarios] piensan y actúan igual que nosotros a su edad, sin darnos cuenta que mantenernos en esa creencia es poner más dificultades para lograr una comunicación más efectiva y finalmente un proceso de enseñanzaaprendizaje más provechoso" (Blanco, 2008, p. 3).

También, en acciones directas desde la docencia sería posible identificar obstáculos para el desarrollo de una buena relación pedagógica en la universidad. Éstas no serían condiciones dadas sino el resultado de prácticas asentadas históricamente como válidas en el ejercicio de la docencia. La soberbia, el desagrado por repetir las explicaciones, el reproche en público, el trato impersonal, el abuso de poder o la percepción de injusticia en las evaluaciones destacan 
como obstaculizadores del vínculo profesor-alumno señaladas por estudiantes en diversas partes del mundo (Al-Hamdan, 2007; Krzemien \& Lombardo, 2006; Cataldi \& Lage, 2004; Rosh, 2004; Halonen, 2001; Bennett 1999).

\section{Método}

Para la realización de la presente investigación se utilizó metodología cualitativa, considerando a ésta la más adecuada para responder a los señalados objetivos del estudio y su objeto de investigación: percepciones de estudiantes universitarios respecto a la relación profesor-alumno a lo largo de su trayectoria académica (Flick, 2004; Ruiz, 1996). Además, esta metodología permite acceder a los datos de manera flexible, considerando elementos emergentes e inesperados en el análisis.

Las carreras elegidas para el estudio representan distintas áreas del conocimiento dentro de la PUC. Con este criterio se definió el siguiente contexto muestral: estudiantes de Arquitectura, Ciencias Biológicas, Educación, Ingeniería y Psicología de $2^{\circ}$ a $5^{\circ}$ año. Se recolectaron datos de estudiantes en distintas etapas de su carrera en el supuesto de que sería posible identificar diferencias cualitativas en las características de la relación profesor-alumno valoradas por ellos, relacionadas con sus años de experiencia estudiantil. Los participantes del estudio fueron seleccionados de manera aleatoria desde tales carreras.

Como técnica de recolección de datos se utilizó el grupo focal, ya que ésta facilita el intercambio de ideas entre los participantes a partir de sus experiencias, percepciones y creencias, brindando así información en profundidad sobre el tema en cuestión (Flick, 2004).

Se realizaron diez grupos focales, dos por carrera, guiados todos por una misma pauta semiestructurada de entrevista. El número de grupos focales fue predefinido en el diseño de la investigación con el fin de recoger información de estudiantes de distintas generaciones 
de todas las carreras elegidas (agrupando a los estudiantes de $2^{\circ}$ con los de $3^{\circ}$ y a los de $4^{\circ}$ con los de $5^{\circ}$ ). Tras el análisis de la información recopilada se constató haber alcanzado una saturación importante de las categorías elaboradas, no considerándose necesario volver sobre la muestra.

Tabla 1. Características de los grupos focales

\begin{tabular}{|c|c|c|c|}
\hline n. ${ }^{\circ}$ grupo Focal & Carrera & Año de estudio & n. ${ }^{\circ}$ participantes \\
\hline 1 & Arquitectura & $2^{\circ}$ y $3^{\circ}$ & 8 \\
\hline 2 & Arquitectura & $4^{\circ}$ y $5^{\circ}$ & 6 \\
\hline 3 & Ciencias Biológicas & $2^{\circ}$ y $3^{\circ}$ & 8 \\
\hline 4 & Ciencias Biológicas & $4^{\circ}$ y $5^{\circ}$ & 8 \\
\hline 5 & Educación & $2^{\circ}$ y $3^{\circ}$ & 8 \\
\hline 6 & Educación & $4^{\circ}$ y $5^{\circ}$ & 8 \\
\hline 7 & Ingeniería & $2^{\circ}$ y $3^{\circ}$ & 8 \\
\hline 8 & Ingeniería & $4^{\circ}$ y $5^{\circ}$ & 8 \\
\hline 9 & Psicología & $2^{\circ}$ y $3^{\circ}$ & 8 \\
\hline 10 & Psicología & $4^{\circ}$ y $5^{\circ}$ & 8 \\
\hline \multicolumn{4}{|l|}{ Totales } \\
\hline \multicolumn{2}{|l|}{10 Grupos Focales } & lumnos participa & \\
\hline
\end{tabular}

La participación de cada grupo focal fue íntegramente transcrita. Los datos fueron analizados en conjunto por el equipo de investigación, siguiendo como criterio de rigor la triangulación entre investigadores, discutiendo y definiendo por consenso la codificación del texto. El análisis se realizó según los procedimientos de la teoría fundamentada (Strauss \& Corbin, 2002), iniciándose con la codificación abierta de los datos obtenidos. Una vez alcanzado un número importante de códigos y creando categorías con aquello que emergía desde los textos analizados, se reorganizó lo recogido para su presentación en función de las dimensiones de relación profesoralumno descritas por Van Manem (1991), utilizando a éstas como referencia para el análisis. Esto permitió generar un relato descriptivo de las distintas categorías ofrecidas por los estudiantes respecto a las características de relación profesor-alumno que favorecerían su aprendizaje y también de aquellas que a su juicio lo obstaculizarían. Posteriormente, los datos se organizaron analíticamente en un modelo relacional. 


\section{Resultados}

A continuación se describirán los principales resultados obtenidos tras el análisis transversal de los datos recogidos en las cinco carreras estudiadas, clasificados en categorías generales de organización basadas en las dimensiones de relación pedagógica ofrecidas por Van Manem (1991), las cuales se han denominado como (1) la persona del profesor, (2) la relación pedagógica y (3) las estrategias instruccionales utilizadas.

En cada categoría se señalan características que facilitarían el encuentro y el aprendizaje así como aquellas que lo obstaculizarían, todas dependientes del actuar del profesor. Por razones de espacio no se hará relación en este artículo a acciones y actitudes dependientes de los estudiantes que influirían en el vínculo pedagógico, quienes reconocen su parte en la configuración de una buena relación. Se ha optado por profundizar en la descripción de aquellas prácticas valoradas y no valoradas por los alumnos que estarían en manos de los docentes, con el fin de extraer orientaciones útiles y esperando ayudar con ello al fortalecimiento del rol educativo de los profesores universitarios.

No obstante lo anterior, es importante hacer una advertencia en relación con las categorías derivadas de este estudio (así como de otros similares). Éstas deben ser tomadas como orientaciones y sugerencias para la acción pedagógica, no como una guía o manual de cómo hacer aplicable por todos y en todo contexto. Siguiendo a Halonen (2001), si bien se asume que prácticas tóxicas en docencia reconocidas por algunos estudiantes serán igualmente nocivas para otros, se entiende también que aquello que funciona bien para algunos profesores puede fallar dramáticamente en otros. Contar con metáforas, tipologías y reglas sólo sirve para dar ciertas luces en una práctica compleja, pero no deben considerarse nunca como normas inflexibles de aplicación. Estas orientaciones deben ser traducidas y asimiladas desde la genialidad y estilo individual de cada docente.

\section{La persona del profesor}

En general, los estudiantes no señalaron características personales de los docentes que influirían en el encuentro aisladas de la relación. 
La edad no surgió como determinante para establecer una buena relación con el profesor, toda vez que señalaron que independiente de la distancia generacional entre ellos podría trascenderla por medio de su propio actuar en la sala de clases.

Sí emergió el prestigio del académico como una característica que podría interferir en la relación pedagógica, favorecería o dificultaría la disposición inicial de los estudiantes. Un docente de prestigio sería motivador para los estudiantes, digno de respeto y admiración, en contraste con los desprestigiados en las facultades, quienes tendrían "barreras de entrada" más altas que derribar para relacionarse con sus alumnos.

\section{La relación pedagógica}

Los juicios de los estudiantes respecto a la disposición con la que sus profesores llegan a hacer clases, actitudes en la propia sala y fuera de ella serían elementos que influirían en la conformación de la relación profesor-alumno.

- Juicios previos de los estudiantes respecto a la disposición del docente a enseñar

Los estudiantes muy rápidamente elaborarían juicios respecto a la disposición con la que sus docentes llegan al aula. En su experiencia, los formarían en las primeras clases, en sus palabras, lograrían "sacar la foto" de inmediato a sus profesores, captando si estos tienen o no motivación por hacer su clase y enseñar o si sus prioridades académicas son otras. Esas opiniones, en ocasiones difíciles de modificar, condicionarían el tipo de relación que desarrollarían con sus académicos.

Los alumnos evalúan la disposición para el encuentro de sus profesores basados en "pruebas" que clase a clase van recogiendo hasta formarse una idea al respecto. Su evidencia la obtendrían desde distintas fuentes: "la cara" con la que el docente llega al aula (entusiasta y animado o apático y desmotivado), su tono de voz, la preparación de las clases o las acciones concretas para vincularse. 
"Se nota en cómo se refiere a ti, en cómo se comunica contigo, en sus opciones de quedarse o no quedarse en el recreo, porque cuando la opción es por ser alguien que está enseñando se va a traducir en conductas que, con más o menos cercanía, te va a dejar siempre la sensación de que la persona te está queriendo enseñar" (Psicología $2^{\circ}$ y $\left.3^{\circ}, 165\right)$.

Cuando los estudiantes captan que sus profesores valoran el contacto con sus alumnos, las condiciones para establecer una buena relación con ellos son favorables.

"claro, hay profesores que catetean harto, que mándenme mails, que llámenme, que al final uno termina perdiendo el miedo y se acerca..." (Arquitectura $4^{\circ}$ y $5^{\circ}$, párrafo 179).

Por el contrario, cuando los estudiantes perciben poca motivación inicial del docente respecto al ramo que ofrece y al encuentro, deducen que no hay interés en la enseñanza y aún menos en relacionarse con los estudiantes, la clase misma sería "un trámite" para el profesor.

"Uno puede tener todas las ganas de conocer al profe pero si el profe no tiene las ganas de conocer... como que en verdad filo poh"” (Ingeniería $4^{\circ}$ y $5^{\circ}$, párrafo 239).

"Hay algunos profes que no son para estos ramos, y que en el fondo no les gusta, y eso se transmite (...) y en el fondo al final eso traspasa a nosotros como que ese ramo pa' nosotros también es una lata" (Psicología $2^{\circ}$ y $3^{\circ}$, párrafo 16$)$.

La prioridad de otras actividades-principalmente investigacioneses para los estudiantes la principal explicación a la falta de interés de algunos profesores por la docencia.

"Como para poder hacer investigación tienen que hacer clases, es un trámite para ellos, algunos van con disposición de trámite no como otros que vienen y te hacen toda la producción y contestan preguntas" (Ciencias Biológicas $2^{\circ}$ y $3^{\circ}$, párrafo 587). 
- Actitudes y acciones del docente durante el desarrollo de la clase En sala de clases, en la cotidianeidad de los encuentros semanales, las actitudes y acciones de cada profesor configurarían las bases de la relación pedagógica que establecerían con sus alumnos. Así como una actitud acogedora favorecería una buena relación, con un reproche o exceso de soberbia se ensancharía la distancia preexistente entre docentes y estudiantes.

Los participantes del estudio dejaron claro que todo lo que sus profesores les han transmitido en sala de clases ha tenido incidencia en el vínculo establecido, nada les ha sido indiferente, incluso aquello que podría ser calificado como accesorio (como el tono de voz que acompaña la frase o la emoción ligada a relatar un fenómeno).

Por ejemplo, a juicio de los estudiantes, los docentes invitarían al aprendizaje cuando por medio de su propio entusiasmo con la materia que enseñan lograrían seducirlos y encantarlos, incluso más allá de sus intereses iniciales.

"Se nota que a él realmente le gusta y quiere enseñar... y como que muestra el carisma en las clases "a mí me gusta esto y se los quiero mostrar y se los voy a tratar de mostrar para ustedes" (Arquitectura $2^{\circ}$ y $3^{\circ}$, párrafo 105).

"Yo iba encantada a ese curso... además que...como que... no era mi fuerte en media ni en básica, entonces siento que aprendí mucho en ese ramo y lo otro es que... ellas enamoraban... a nosotros nos enamoraban con lo que ellas nos estaban tratando de enseñar" (Educación $4^{\circ}$ y $5^{\circ}$, párrafo 291).

Para los estudiantes sería un potencial de todo docente en la sala de clases "abrir la mente" de los alumnos al conocimiento, incluso de aquellos no interesados o indiferentes a la materia. Ello se entiende como "enganchar", despertar la inquietud por entender, motivar a realizar el esfuerzo de dedicar tiempo y energía a aprender algo. Esto lo lograrían profesores que buscan dar sentido a su enseñanza, ligando el aprendizaje presente de los estudiantes con su desarrollo futuro como profesionales o manifestando el propio sentido que la materia implica para él. 
"Yo creo que lo más importante es que ellos están formando científicos y nosotros esperamos que nos formen como tales, nosotros nos queremos creer el cuento y necesitamos que alguien que ya es científico nos haga creer el cuento" (Ciencias Biológicas $2^{\circ}$ y $3^{\circ}$, párrafo 593).

"Yo creo que la cuestión es la intención, el ánimo... en darle un sentido, personalmente pa mí que le den un sentido siempre es más trascendental [... ] pa qué se hace, pa qué sirve" (Ingeniería $4^{\circ}$ y $5^{\circ}$, párrafo 374 ).

También invitaría al aprendizaje la percepción de los estudiantes de que su profesor confía y cree que todos pueden aprender. Esta actitud se transmitiría en el aula, en el esfuerzo por formar y no dejar a ningún alumno atrás, en que al hablar se dirija a todo el curso y no sólo a los de adelante, por ejemplo.

Por el contrario, no invitaría al aprendizaje el percibir en la sala de clases una distancia inabarcable entre el conocimiento del profesor y las capacidades de los estudiantes. La soberbia de algunos docentes habría generado en la trayectoria de los participantes del estudio la sensación de que el saber mismo, aquello que debería ofrecer y entregar a sus alumnos, puede llegar a convertirse en una barrera importante para el encuentro.

"Unos son súper soberbios y otros súper ensimismados, como que creen que son un tipo de Dios frente al alumno que son capaces de no hablarte, no te miran" (Arquitectura $2^{\circ}$ y $3^{\circ}$, párrafo 74 ).

Los estudiantes valorarían sentirse reconocidos por sus profesores más allá del papel de alumnos cuando perciben que la clase no está destinada hacia una audiencia anónima o estándar sino dedicada a ellos en particular. Esto sería evidente cuando el docente conoce (o intenta conocer) el nombre de sus alumnos, se muestra empático ante sus necesidades y comprensivo con sus dificultades.

"Que te llame por el nombre es como "ioh! conoce mi nombre", aunque sea el apellido, el apellido ya está bien, pero mi nombre es como "oh...sabe mi nombre 
de pila" eso ya es como lo máximo" (Ingeniería $4^{\circ}$ y $5^{\circ}$, párrafo 217).

La empatía entre profesores y alumnos se expresaría en docentes que lograrían ponerse en el lugar de sus estudiantes, comprendiendo que su vida es más que una serie de ramos por aprobar, tomando en cuenta el "estado de ánimo" del curso durante el semestre, en especial cuando la sobrecarga académica o problemas individuales se hicieran evidentes en el rendimiento.

"La clase se hace súper amena gracias a que el profesor está súper consciente que no está tratando con un niño o no está tratando con un mueble sino que está tratando con personas..." (Educación $2^{\circ}$ y $3^{\circ}$, párrafo 13 ).

Asimismo dentro del reconocimiento como actitud valorada por los estudiantes, éstos consideraron positivo que los académicos respeten su opinión, aun cuando sea opuesta, y que sean respetuosos con sus preguntas. En ello se haría manifiesta la valoración de los alumnos como sujetos con saberes válidos y admisibles en el aula.

El reverso de la cercanía y reconocimiento de los alumnos por parte de los profesores serían la lejanía afectiva y la falta de conexión con ellos, las que constituirían obstáculos para la relación pedagógica reconocidos por los participantes del estudio.

"Hay un aura como de omnipotencia que tienen los profesores cuando están en clases, nada de conectarse un poco con el alumno. Ellos están sobre un pedestal, emanando una cierta información, contando, y que nosotros debiéramos entender simplemente porque ellos la están explicando" (Ciencias Biológicas $4^{\circ}$ y $5^{\circ}$, párrafo 36).

La humildad y cercanía en el trato serían actitudes valoradas por los estudiantes, reconocidas en profesores con los que habrían logrado generar relaciones positivas a lo largo de sus trayectorias. Estos profesores nunca imponían ni intimidaban con su saber a los estudiantes, lo que, a juicio de éstos, ayudaba a disminuir la distancia entre ellos. 
Por otro lado, los estudiantes señalaron valorar el buen manejo de grupo desarrollado por algunos profesores, lo cual favorecería su interés, respeto y confianza en ellos y por la docencia ofrecida. Por buen manejo de grupo los estudiantes describieron a profesores que, sin ser autoritarios ni laxos en su trato, habrían logrado frente a la clase surgir como una figura de autoridad, como un líder en cuanto al proceso a seguir.

Lo opuesto a una figura de autoridad para los estudiantes serían aquellos profesores en los que habrían percibido abuso de poder desde el rol docente. Situaciones como descalificaciones públicas (individuales o grupales), malos tratos verbales, comparaciones, generalizaciones de lo negativo y cambio en criterios de evaluación del curso, entre otras decisiones arbitrarias, serían acciones que al menos una vez a lo largo de su carrera habrían experimentado los participantes de la investigación, manifestando abierto rechazo a tales prácticas autoritarias.

"Le pregunté algo y me miró y me dijo jah usted es tonta, acabo de repetir eso como tres veces! y en verdad no lo había repetido, lo había dicho la clase pasada" (Ciencias Biológicas $2^{\circ}$ y $3^{\circ}$, párrafo 306 ).

"No tienen tino pa' decir las cuestiones, o sea uno puede decir "esto está pésimo" de muchas maneras (...) se puede decir lo mismo de una manera más constructiva, en vez de decir "por qué trabajaste dos semanas en esa mugre" (Arquitectura $4^{\circ}$ y $5^{\circ}$, párrafo 51).

Actitudes docentes evaluadas por los estudiantes como abusos de poder les colocan en una posición defensiva, les llevan a evitar la interacción o a no sentirse a gusto en clases.

"Llegan y como que imponen, entonces como que da miedo...y ahí como que uno no participa y si uno no participa...el profesor no se va a acercar y si no se va a acercar...y al final es como un círculo" (Educación $2^{\circ}$ y $3^{\circ}$, párrafo 292). 
En el otro polo del autoritarismo, habría docentes que al parecer de los estudiantes pierden el norte de la relación (el aprendizaje), cayendo en exceso de "buena onda", restando seriedad y exigencia al proceso de aprendizaje. Permitir que los estudiantes se "tomen el codo" tampoco contribuiría a establecer una relación pedagógica positiva para aprender. Ellos aspiran a ser exigidos con justicia.

Al recordar a profesores que durante su trayectoria académica habían emergido como autoridad respetada y apreciada por los estudiantes, favoreciendo con ello una buena relación pedagógica, los estudiantes señalaron como característica distintiva de ellos el ser figuras accesibles, "humanos" y justos, capaces de poner límites y reglas básicas de coordinación para el trabajo del curso.

- Acciones del docente fuera de la clase

Para los estudiantes ha resultado importante percibir en sus docentes buena disposición al encuentro y sentirse acogidos cuando han acudido a ellos fuera del horario de clases (presencialmente o vía e-mail). Cuando perciben o suponen mala disposición de sus profesores al contacto, dejan de buscarlos.

"no te contestaba nunca más en la vida, al profe tú le mandabai una duda y nunca supiste si le llegó, si lo leyó, si no... o en verdad no le importaba" (Ciencias Biológicas $4^{\circ}$ y $5^{\circ}$, párrafo 30 ).

\section{Las estrategias instruccionales utilizadas}

Los estudiantes reconocen a través de su trayectoria buenas prácticas docentes ligadas a la enseñanza, las han experimentado y saben que su aprendizaje se ha potenciado por ellas. También reconocen acciones que no los motivan o que no les han ayudado a aprender. En la configuración de la relación profesor-alumno este tipo de dinámicas también cumpliría un papel. Los estudiantes derivan de la preocupación por enseñar bien, preparar las clases y generar una buena experiencia de aprendizaje una valoración de ellos como alumnos y profesionales en formación. 
- Formas de organización del contenido y medios utilizados por el profesor

Los estudiantes señalaron ser capaces de reconocer cuando un docente prepara su clase o no y tal preocupación sería bien recibida y motivaría al aprendizaje. Valoran tanto la preocupación en la forma de impartir el conocimiento como la elección del contenido entregado.

Formas valoradas por los estudiantes de entregar la materia resultaron diversas, desde clases activas con discusiones y diálogo, debates y trabajos grupales, hasta la forma expositiva en la que el profesor hace un relato interesante, apoyado con material audiovisual o simplemente con su capacidad de argumentar. Lo importante para los alumnos sería poder seguir el hilo de aquello que quiere transmitir, manteniéndose motivado y atento con la clase.

"Cuando un profesor explica bien la materia y se entiende, uno sigue dentro" (Ingeniería $2^{\circ}$ y $3^{\circ}$, párrafo 60).

La incorporación del humor como un recurso para retomar la atención de los alumnos, "despertarlos" y distender el ambiente resultó un medio valorado por los estudiantes. La utilización de inflexiones de voz durante la clase también sería apreciada, echada de menos en casos de profesores "monocordes".

"Que no sean tan planos es muy importante (...) es un poco agotador, escucharlo hablando así con voz lenta y baja" (Arquitectura $2^{\circ}$ y $3^{\circ}$, párrafo 33 ).

Formas no valoradas de entregar la materia señaladas por los estudiantes son las clases monótonas en las que el profesor se limitaría a la lectura de sus diapositivas o la ejecución de un monólogo, sin gran intercambio de opiniones ni espacios de discusión para los estudiantes.

"Hay cursos que son terribles y el profe no logra motivar a nadie, o sea, habla, habla, habla..." (Ingeniería $4^{\circ} \mathrm{y}$ $5^{\circ}$, párrafo 167).

"Igual encuentro que no nos hacen reflexionar mucho o debatir en cuanto a algunos temas en que se podría 
debatir (...) encuentro que es como pasar materia, esa es la función y listo" (Ciencias Biológicas $2^{\circ}$ y $3^{\circ}$, párrafo 31).

Los estudiantes son muy críticos con aquellos docentes que no renuevan su material de diapositivas o cuando su confección es poco cuidadosa (la letra es demasiado pequeña para leer o sólo es texto copiado y pegado, con una sobrecarga de la lámina).

Respecto al contenido seleccionado por los profesores para impartir la materia, para los estudiantes sería motivador que éste vaya más allá de las lecturas del curso. Para ellos ir a clases debe tener el "valor agregado" de poder aprender más de lo que harían leyendo la materia o buscando por internet, para lo cual se perciben capaces. El profesor debe emerger como un factor necesario para entender el curso, un mediador que posibilite comprender cosas que por sí solos los estudiantes no podrían alcanzar.

"Uno dejaba de ir a clases y por mucho que te consiguieras los apuntes lo más seguro es que tú entendieras un cuarto de lo que entendieras yendo a clases" (Arquitectura $2^{\circ}$ y $3^{\circ}$, párrafo 183).

Cuando el contenido de las clases es el mismo de los textos (incluso textualmente plasmado en las diapositivas), la motivación de ir a clases disminuye y las posibilidades de encuentro con los docentes también.

Resulta estimulante para los estudiantes poder admirar a sus profesores por la capacidad de expresar en clases su saber respecto a la materia de una manera comprensible para todos, traduciendo aquello complejo que domina, aterrizando sus contenidos en unos casos, subiendo de nivel en otros "sin soltar la mano" de sus alumnos.

"cuando yo siento que estoy frente a alguien que sabe mucho de lo que está hablando, también... me encanta... hace que yo ponga atención" (Educación $2^{\circ}$ y $3^{\circ}$, párrafo 226). 
Un profesor que logra "aterrizar los contenidos" sería un buen pedagogo para los estudiantes. Relacionar la materia abstracta o lejana con aquello que es conocido por los alumnos sería una capacidad importante que facilita el aprendizaje. Ellos señalan diversas estrategias efectivas utilizadas por sus docentes para ayudarles a entender contenidos complejos, entre ellas las analogías y las metáforas.

"Cuando tú estay como metido dentro de la capa lipídica y que son cosas tan chicas (...) pero cuando te lo conectan con algo que te pasa, por ejemplo, que esto significa que tenís que comer más plátano por ejemplo, o tomarte no sé qué... eso a mí me gusta, que te conecten con cosas de la vida real y que veí' siempre, porque si no estay como volao en una cuestión que no veí' nunca, como que no lo podí' aprender en verdad" (Ciencias Biológicas $2^{\circ}$ y $3^{\circ}$, párrafo 114).

"un profesor puede tener tantos conocimientos... pero si no te lo plantea de una forma más contextual, aterrizado a la realidad, yo creo que se pierden o que uno no los adquiere...como... no sé po'... como que pasan de largo" (Educación $4^{\circ}$ y $5^{\circ}$, párrafo 307 ).

Los estudiantes valoran que los docentes desarrollen actividades prácticas con los contenidos, lo que les permitiría entender mejor la materia, relacionándola con ejemplos concretos de aplicación, mejorando la retención de lo aprendido (usos prácticos, laboratorios, talleres, salas espejo, etc.).

"Me servían mucho los laboratorios porque después, por ejemplo, para un control me acordaba... yo tuve en la mano y veía cómo cambiaba de un color a otro por ejemplo" (Ciencias Biológicas $2^{\circ}$ y $3^{\circ}$, párrafo 144).

Por el contrario, no los motivaría el aprendizaje memorístico que se privilegiaría en algunas clases (evidenciado en las evaluaciones en donde deben repetir y no producir algo nuevo con los contenidos, como ocurriría en pruebas de aplicación).

Los estudiantes también valoran que el docente les facilite ligar lo que aprenden con su futura vida profesional, formarse desde la 
experiencia de sus docentes (o de invitados del mundo profesional) a través de anécdotas y relatos de aplicación.

"Me parece motivante cuando los profesores tratan de aterrizar un poco más lo que es la carrera con la realidad (...) porque... alguien con medicina puede ver desde un principio en que va a trabajar un médico, pero un ingeniero... uno en primer año pregunta "¿qué hace un ingeniero?” (Ingeniería $4^{\circ}$ y $5^{\circ}$, párrafo 621 ).

- Organización de los alumnos para los fines de aprendizaje A juicio de los estudiantes un buen profesor guía a sus alumnos hacia el aprendizaje de manera tal de no entregar todo "en bandeja", promoviendo que reflexionen y encuentren por sí mismos las respuestas con su apoyo y compañía.

"Pa' mí no era ir y tener las cosas al frente y buscar la respuesta en el profe, era yo necesitar algo, pero en caso de necesitar algo y que escapara de mis capacidades, yo tenía completo acceso al profesor y el profesor no tenía problema en ayudarme... la idea del curso no era que el profe me diera la respuesta sino yo encontrar mi respuesta" (Ciencias Biológicas $2^{\circ}$ y $3^{\circ}$, párrafo 158 ).

Para los estudiantes, un buen profesor sabría dar a cada quien lo que necesita, regula su apoyo, su cercanía o lejanía de acuerdo a las necesidades de sus estudiantes.

"preguntaba también si alguien tenía dudas, de repente cachaba también a quien le costaba más y siempre le preguntaba a ellos" (Ingeniería $4^{\circ}$ y $5^{\circ}$, párrafo 32 ).

Un docente que motiva al aprendizaje promueve la reflexión, incentiva la discusión respecto al contenido, genera debates, ofrece la palabra a los alumnos para elaborar sus ideas en el aula. Él lidera y modera la participación.

Por cierto, tales estrategias instruccionales difícilmente tendrían cabida en un espacio de aprendizaje en donde la relación pedagógica 
con el profesor no es grata o generadora de confianza. Se profundizará al respecto en el siguiente apartado.

\section{Discusión}

Las distinciones utilizadas para presentar los datos sirven como "lentes" para mirar en detalle elementos comunes que emergieron desde los grupos focales. Puestas en escena, tales categorías interactúan, se intercalan y sus límites se vuelven difusos. La distinción será válida para observar la docencia y pensar respecto a la relación pedagógica en la universidad, no obstante, este estudio asume que un fenómeno complejo como el descrito no se reduce a las categorías reportadas y se requieren mayores investigaciones al respecto.

Tras la observación de los datos recogidos, es posible distinguir elementos comunes transversales valorados por estudiantes de las distintas generaciones y carreras estudiadas, que podrían permitir comprender sobre qué aspectos de la relación profesor-alumno se sustentan experiencias académicas satisfactorias.

Relación pedagógica (dimensión bidireccional), base de la relación profesor-alumno.

Lo que se ha distinguido como relación pedagógica se refiere al vínculo entre educadores y educandos sin considerar el contenido, sino las operaciones y acciones realizadas para "preparar el terreno" hacia el aprendizaje. Para establecer un buen contacto los estudiantes demandan reconocimiento y valoración, quieren ser invitados al aprendizaje, necesitan ser encantados por sus profesores, sentir un real interés por que ellos aprendan, no una asamblea anónima sino que ellos en particular.

Considerando lo señalado, pareciera que debe haber alguna forma de seducción en el proceso de enseñanza, una búsqueda activa por interesar al estudiante en el contenido y en la clase misma, utilizando para ello elementos que conquisten su interés hacia el aprendizaje: el prestigio del académico(a), su experiencia profesional, su conocimiento, su simpatía, su antipatía, la utilidad futura del 
contenido enseñado, entre otros. Ellos buscan cierta seducción, entendida como una invitación a hacerse presentes en la clase, más allá de la mera asistencia. No obstante, dejan en claro que una buena relación profesor-alumno no se obtendrá basada sólo en ello. Menos el aprendizaje. Ellos quieren aprender y esperan que lo que se les enseñe sea de calidad y que por más buena que sea la relación, esto no implique un desmedro en la exigencia o en el nivel de lo enseñado.

En este sentido, para ser valorado y entablar una buena relación pedagógica no bastaría con actuar como el docente del experimento del doctor Fox (Bain, 2004), siendo alguien que sólo seduce y encanta, entretenido, sin importar el contenido ofrecido. Los estudiantes juzgan el interés del profesor por sus alumnos en función de otros aspectos tales como la calidad del contenido y la pertinencia de lo aprendido en relación con su futuro laboral. Los estudiantes captan cuando la relación "pierde el norte" y son críticos al respecto.

Es posible que muchos docentes consideren que no son "suficientemente" carismáticos y que encantar a los estudiantes será para ellos tarea difícil. Frente a tal aprensión es importante notar que, más allá de estilos de acercamiento (carismático o tímido, directivo, supervisor o participativo), pareciera ser que desde la perspectiva de los alumnos la intención del encuentro es lo que vale. Ellos aprecian y valoran a un profesor que auténticamente busca establecer un vínculo con ellos y es capaz de transmitirlo.

Resulta interesante también destacar que, desde la perspectiva de los estudiantes, serían los docentes los encargados de dar "el primer paso" para establecer una buena relación. Si ellos "invitan", ellos siguen. Si no, será más difícil que se dé una cercanía. Esto se debe entender desde la perspectiva de los estudiantes, en particular de primeros años: la asimetría jerárquica es enorme y la posición desde donde se observa a los académicos es distante e idealizada. Es más fácil en esa circunstancia que el profesor que está "arriba", "baje", a que los alumnos "suban" hasta ellos.

Considerando lo señalado por los estudiantes, la dimensión bidireccional de la relación profesor-alumno (Van Manem, 1991), 
que en el análisis se ha llamado relación pedagógica, pareciera ser la primera piedra, la estructura sobre la que luego se podrá instalar un buen clima de aula (Arón \& Milicic, 1999). Serían estos los cimientos desde donde el docente podrá transmitir sus conocimientos, apoyándose luego en variadas estrategias instruccionales.

\section{Clima social de aula en el contexto universitario}

Tras analizar lo descrito, es posible considerar que un buen clima social de aula en la universidad, basado en una buena relación pedagógica, se emparienta con lo que Milicic y Arón (2000) han denominado clima nutritivo para el contexto escolar. En un clima nutritivo los participantes se sienten reconocidos y valorados, predomina una percepción de justicia en cuanto a las normas y reglas que regulan las relaciones, la valoración positiva es común entre los miembros y los logros son reconocidos de manera explícita. Asimismo, favorece el sentimiento de pertenencia, el crecimiento personal y la creatividad y hace que cada miembro se pueda percibir a sí mismo como valioso.

En un aula universitaria en la cual los estudiantes perciben buena relación con sus docentes, se sienten reconocidos y respetados como sujetos con opinión y conocimiento, identifican al profesor como una autoridad que confía en ellos y se sienten valorados y con libertad de participar y crecer desde su aprendizaje. Es en esos contextos donde señalan encantarse con su carrera y su propio proceso profesional, involucrándose de mejor manera con su formación, condición indispensable para la educación. En la ligazón entre formación e identidad se juega parte del éxito de la labor educativa y del aprendizaje de los alumnos. De tal relación se desprende la inversión cognitiva del estudiante, la motivación puesta en la tarea y sus afectos ligados con el aprendizaje (Bourgeois, 2000).

Volviendo al paralelo entre el clima social de aula escolar y el universitario, características de mala relación con los docentes en la universidad referidas por los estudiantes se condicen con lo que Milicic y Arón (2000) han llamado climas tóxicos, en donde cada miembro participante se percibe invisible, sólo reconocido en ocasiones debido a defectos y errores, con una vívida percepción de 
rigidez y arbitrariedad en las normas aplicadas a la convivencia interna y las evaluaciones, primando un trato autoritario en las relaciones.

En un aula universitaria en la cual los estudiantes no perciben buena relación pedagógica, reconocen poco interés del profesor por el encuentro, por conocerlos, por verlos más allá de un rol anónimo de alumno ("somos un número"), catalogan al docente como lejano y soberbio, poco afectivo y con tendencia a abusar del poder de su posición, autoritario, descalificador y poco asertivo en sus comentarios.

Las características de lo que se ha llamado clima nutritivo en el contexto universitario como las de clima tóxico han sido reconocidas en anteriores estudios respecto a la relación pedagógica en la universidad (Al-Hamdan, 2007; Krzemien \& Lombardo, 2006; Cataldi \& Lage, 2004; Rosh, 2004; Halonen, 2001; Bennett 1999).

Estrategias instruccionales: infinitas posibilidades de hacer para el aprender

Buenas estrategias de enseñanza juzgadas por los estudiantes se sustentan en (y promueven además) un buen vínculo y un buen clima de aula. La gratitud de los estudiantes hacia sus académicos expresada ante la percepción del esfuerzo con el cual ellos buscan encantarlos, motivarlos y enseñarles da cuenta de aquello.

La posibilidad de innovar de un docente dentro del aula, yendo más allá de lo expositivo, invitando a la participación, promoviendo discusiones o siendo capaz de profundizar en contenidos sin "dejar atrás" a sus estudiantes se basaría en el buen vínculo y el clima establecido en el aula. 
Figura 1

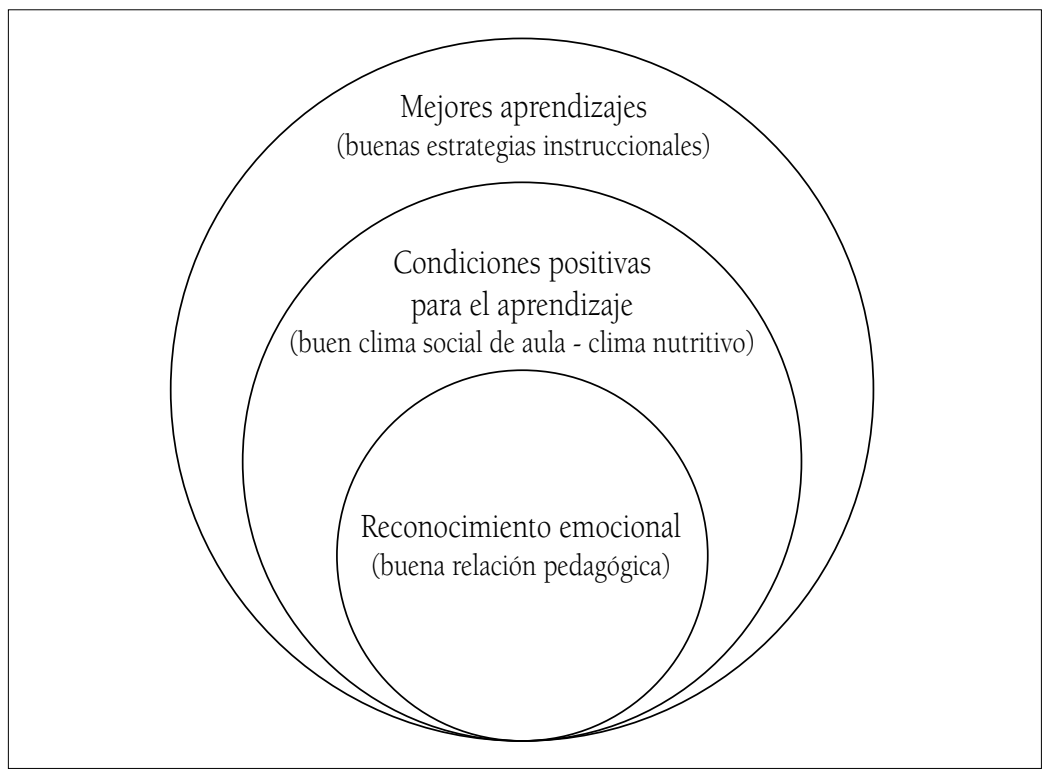

Si el docente logra llegar a sus alumnos mediante sus estrategias instruccionales, el vínculo se hará aún más fuerte, los estudiantes reconocerán su intención por enseñarles y, tal como señalan ellos, los aprendizajes serán de mejor calidad.

Al considerar las estrategias instruccionales más valoradas por los estudiantes, es posible detectar en todas ellas el interés del profesor por "personalizar" sus esfuerzos hacia el curso, haciendo viva la enseñanza y no un proceso mecánico, independiente de su audiencia. Si las acciones del docente consideran en su origen las necesidades de sus estudiantes, ellos reconocen tal preocupación.

\section{Conclusiones}

Tras la realización del presente estudio, es posible señalar que la experiencia de aprendizaje de un estudiante se enriquece cuando con su docente construye un buen vínculo pedagógico. Si bien es válido asumir que en otras condiciones de relación es posible adquirir conocimientos, para los estudiantes resulta evidente que su educación adquiere valor cuando es realizada en el contexto de buenas relaciones 
con sus educadores, las que ofrecen un contexto ambiente protegido para la exploración, la duda, el error y el triunfo. Se aprende más y mejor cuando en el aula se asiste con agrado, cuando se percibe buen trato desde sus educadores, cuando cada uno se siente valorado y reconocido (Bourgeois \& Nizet, 1997, en Sebastián, 2007).

Es importante insistir respecto a que serían los docentes los llamados a ejecutar los primeros pasos para avanzar hacia una buena relación pedagógica, en especial con los alumnos de primeros años, en quienes se percibió una mayor distancia respecto a sus profesores y una mayor necesidad de apoyo y estructuración de la experiencia académica. Considerando que estos estudiantes son los más expuestos a desertar (González \& Uribe, 2002), sería clave apoyar a los docentes de primer y segundo año para fortalecer sus posibilidades de establecer una relación pedagógica positiva con sus estudiantes. Ellos valoran el esfuerzo dedicado, la paciencia y el afecto puesto en la enseñanza. En otras palabras, si bien la primera impresión importa, la relación se pone en juego en el día a día, clase a clase. La relación y un buen clima se construyen con la paciencia de un artesano y no sólo con una buena "entrada" a escenario.

Si bien en este estudio se asume que no hay recetas para establecer una buena relación pedagógica, es posible reconocer factores comunes que la facilitan: el reconocimiento emocional de los estudiantes (valorar sus necesidades individuales y grupales para el aprendizaje), el acercamiento activo hacia ellos, una invitación atractiva hacia el aprendizaje, la búsqueda constante de la perfección y la excelencia y la realización de cada clase de forma consciente y paciente, conectada con la audiencia, preparada para ella y sus demandas. Por el contrario, la lejanía afectiva, el autoritarismo, la falta de reconocimiento del otro, la enseñanza "automática" y la presencia de cualquier forma de mal trato o falta de cuidado con los estudiantes llevará a la generación de una mala relación profesoralumno, provocando desgano con el aprender y un clima tóxico para quienes "respiren el mismo aire" en aquella sala de clases.

Establecer en cada aula universitaria climas nutritivos para el aprendizaje y el desarrollo personal de todos los involucrados 
agrega valor a la enseñanza universitaria, implica encantar y motivar a estudiantes cada vez más diversos, con su educación y su desarrollo profesional. Las experiencias académicas que han marcado positivamente las trayectorias de los alumnos se encuentran estrechamente asociadas a buenas relaciones con sus docentes. Para lograrlo, cada académico ha de encontrar su propio estilo con el tiempo y la experiencia, apoyado por su universidad, reflexionando sobre su práctica como educador, dialogando con sus colegas, planificando sus clases desde la mirada de sus estudiantes.

\section{Referencias bibliográficas}

Al-Hamdan, Jasem (2007) Higher Education Classroom Management: Kuwait University Student's Views. En College Student Journal, Vol. 41, (3), pp. 527-582.

Arón, Ana María \& Milicic, Neva (1999) Clima social escolar y desarrollo personal. Un programa de mejoramiento. Santiago: Editorial Andrés Bello.

Bain, Ken. (2004) What the best College Teachers Do. Cambridge: Harvard University Press.

Batanaz, Luís (1997) Las Variables de Relación Profesor-Alumno en el contexto universitario.

Disponible en http://www.aufop.com/aufop/uploaded_files/ articulos/1224194277.pdf.

Bennett, Patricia (1999) Universitarios y Académicos: Una Percepción Juvenil de los Adultos. En Revista de Ciencias Sociales Universidad José Santos Ossa. Antofagasta. Vol. 1, (1), pp. 89-99.

Berríos, Paulina (2007) Análisis sobre las profesoras universitarias y desafíos para la profesión académica en Chile. En revista Calidad en la Educación, (26), pp. 39-53.

Berríos, Paulina (2008) Carrera académica: análisis empírico de su estructura y organización en Chile. En revista Calidad en la Educación, (29), pp. 36-62.

Bourgeois, Etienne (2000) Le sens de l'engagement en formation. En J.M. Barbier \& O. Galatanu, Signification, sens, formation. Paris: Presses Universitaires de France.

Blanco, Luis Ernesto (2008) El estudiante que tenemos. En revista Carta de Ausjal de la Asociación de Universidades Confiadas a la Compañía de Jesús en América Latina, (26), p. 3. 
Casassus, Juan (2006) La Educación del Ser Emocional. Santiago de Chile: Indigo, Cuarto Propio.

Cataldi, Zulma \& Lage, Fernando (2004) Un nuevo Perfil del Docente Universitario. En Revista de Informática Educativa y Medios Audiovisuales, Universidad de Buenos Aires, Vol. 1, (3), pp. 28-33.

Coldren, Jeffrey \& Hively, Jodi (2009) Interpersonal Teaching Style and Student Impression Formation. En College Teaching, 57, (2), pp. 93-98.

Donoso, Sebastian \& Cancino, Víctor (2007) Caracterización socioeconómica de los estudiantes de educación superior. En revista Calidad en la Educación, (26), pp. 203-244.

Flick, Uwe (2004) Introducción a la investigación cualitativa. Madrid: Morata.

Freire, Paulo (1997) Pedagogía de la autonomía. Saberes necesarios para la práctica educativa. México: Siglo XXI.

González, Luis y Uribe, Daniel (2002) Estimaciones sobre la repitencia y deserción en la educación superior chilena. Consideraciones sobre sus implicancias. En revista Calidad en la Educación, (17), pp. 75-90.

Halonen, Jane S. (2001) Beyond Sages and Guides: a Postmodern Teacher's Typology. Paper presented at the Annual Meeting of the American Psychological Association (APA).

Houssaye, Jean. (1998) Le triangle pédagogique. Bern: Peter Lang.

Krzemien, Deisy \& Lombardo, Enrique (2006) Rol Docente Universitario y Competencias Profesionales en la Licenciatura de Psicología. En Psicología Escolar e Educacional. Vol. 10, (2), pp. 173-186.

Milicic, Neva \& Arón, Ana María (2000) Climas Sociales Tóxicos y Climas Sociales Nutritivos para el desarrollo personal en el contexto escolar. En revista Psykhe, Vol. 9. pp. 117-124.

Rosh, Naomi (2006) Tertiary education in the noughties: the student perspective. En Higher Education Research \& Development, Vol. 25, (3), pp. 231-246.

Ruiz, José Ignacio (1996) Metodología de la Investigación Cualitativa. Bilbao: Universidad de Deusto.

Sebastián, Christian (2007) La diversidad interindividual como una oportunidad para el aprendizaje de los estudiantes de educación superior. En revista Calidad en la Educación, (26), pp. 8-101.

Sebastián, Christian \& Scharager, Judith (2007) Diversidad y educación superior. Algunas reflexiones iniciales. En revista Calidad en la Educación, (26), pp. 19-36. 
Smith, Patricia \& Ragan, Tillman (1999) Instructional Design. New Jersey: Prentice Hall.

Strauss, Anselm \& Corbin, Juliet (2002) Bases de la investigación cualitativa: técnicas y procedimientos para desarrollar la teoría fundamentada. Colombia: Ed. Universidad de Antioquia.

Terenzini, Patrick; Pascarella, Ernest \& Blimling, Gregory. (1999) Students' Out of Class Experiences and their Influence on Learning and Cognitive Development. En Journal of College Student Development, 40, 5, pp. 610-623.

UNESCO (1998) La Educación Superior en el Siglo XXI: Visión y Acción. Informe Final Conferencia Mundial sobre la Educación Superior. Paris: UNESCO.

Van Manem, Max. (1991) El significado de la sensibilidad pedagógica. Barcelona: Paidós. 